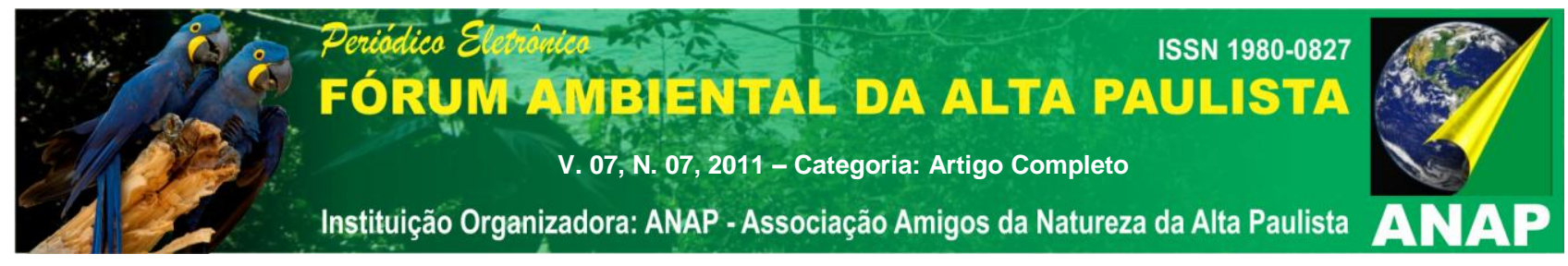

\title{
ANÁLISE DA CORRELAÇÃO DA PRODUÇÃO ENTRE A CANA- DE-AÇÚCAR E A CARNE BOVINA NA EDR DE TUPÃ
}

\author{
Adriano Caetano de Souza \\ Estevam Horie Ruiz \\ Allanna Nigro Cardia dos Santos \\ Camila Pires Cremasco \\ Luís Roberto Almeida Gabriel Filho
}

\begin{abstract}
RESUMO: Este trabalho visa expor a análise de dados entre a produção de cana-de-açúcar e carne bovina, em especial na região de Tupã no estado de São Paulo. Consoante há de se observar que discrepâncias ocorrem em relação à produção de cana-de-açúcar e a carne bovina, demonstrado por intermédio dos gráficos obtidos nessa análise. O estado de São Paulo concentra em torno de 6 à $7 \%$ do total de rebanhos bovinos no Brasil, onde em contrapartida o estado de São Paulo é o maior produtor de cana-de-açúcar concentrando em torno de $57,6 \%$ da produção no Brasil. Tendo em vista isso, foram coletados dados do IEA-SP, e posteriormente foi feita a correlação de ambos que reforçou essa discrepância tanto na região de Tupã-SP como no estado de São Paulo o que implica no aumento de preços na carne bovina vendidas em varejos e supermercados, bem como a preocupação com os efeitos advindos da produção canavieira.
\end{abstract}

Palavras- chave: cana-de-açúcar, carne bovina, correlação.

\section{INTRODUÇÃO}

No que tange a produção de carne bovina, Pacheco e Yamanaka (2006) apontam que o Brasil é o maior produtor de carne bovina do mundo, onde em 2006 o Brasil possuía em média 198 milhões de cabeças de gado, sendo a região Centro-oeste a maior produtora, concentrando em média $34,2 \%$ da produção total no país. 


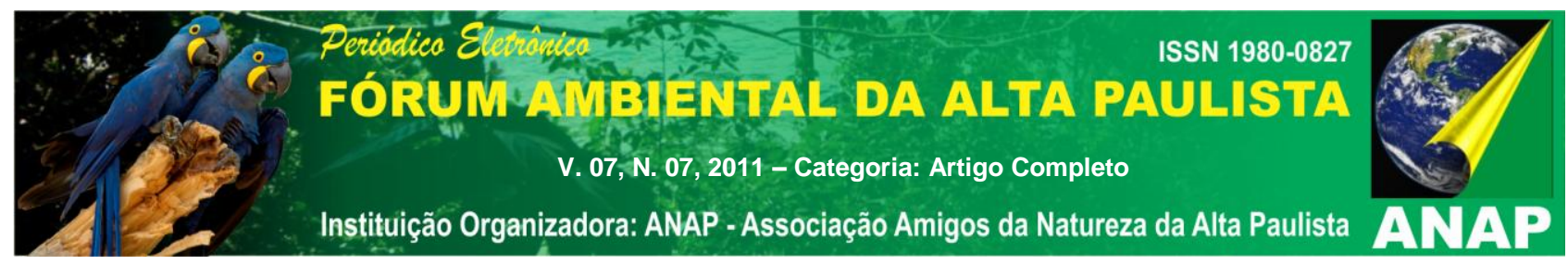

O estado de São Paulo concentra um percentual de rebanho que está entre $6 \%$ e 7\% da produção total no país. Em contrapartida, segundo o Anuário Brasileiro da Canade-açúcar (2010), proveniente do SEBRAE, a região Sudeste é a maior produtora de cana de açúcar, concentrando em média 67,7\% da produção brasileira, e o estado de São Paulo concentra a maior quantidade produzida na região, representando $57,6 \%$ da produção em escopo nacional da cana-de-açúcar.

Durante a expansão da cana-de-açúcar na safra 2007/2008, a incorporação de novas terras na região Centro-Sul para a expansão da produção canavieira foi de 617 mil hectares. Entretanto, cerca de 65\% das áreas incorporadas eram dedicadas as pastagens de bovinos (BRASIL, 2008).

Outro ponto interessante dá-se na participação de terceiros, onde na mesma safra já citada, aproximadamente $42 \%$ da cana-de-açúcar moída no estado de São Paulo pertencia a terceiros (BRASIL, 2008).

Para a elaboração deste trabalho foram gerados dados primários a partir de dados obtidos junto à órgão vinculados ao governo, no que tange a geração de gráficos comparativos provenientes do mesmo.

Também foram utilizadas informações provenientes de diversas publicações concernentes tanto ao setor de cana-de-açúcar quanto ao setor de carne bovina. Vários bens despertam a atenção como açúcar, cachaça e em especial o etanol, incluída ainda a geração de energia que podem ser geradas a partir da cana-de-açúcar.

O objetivo deste trabalho é mostrar por métodos quantitativos a expansão da canade-açúcar na região de Tupã no período de 2004 a 2010 e a ocorrência do comportamento inverso para produção de carne bovina, bem como as conseqüências desse fenômeno para os consumidores em geral e as possíveis ações governistas que amenizariam os resultados negativos para os consumidores.

\section{MATERIAIS E MÉTODOS}




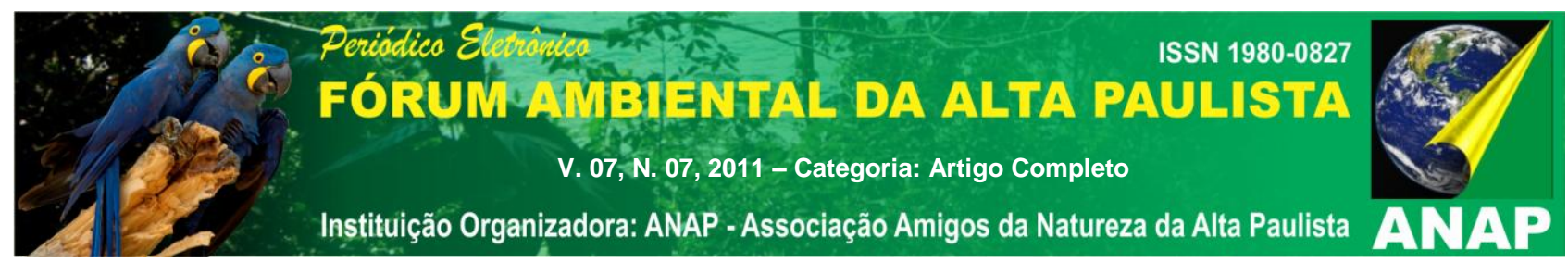

Para fazer a análise entre a produção de cana-de-açúcar e carne bovina foram utilizados dados primários, como dados numéricos que proporcionou a geração de gráficos e sua posterior análise (MARCONI; LAKATOS, 2006) e em relação aos dados secundários foram utilizadas publicações referentes aos setores.

A obtenção de dados necessários para elaboração do presente trabalho foi obtida através do Instituto de Economia Agrícola (IEA). Concernente a obtenção de dados primários, foram utilizadas publicações com dados numéricos proveniente deste instituto referentes à produção de cana-de-açúcar e carne bovina, representando quantidade produzida, receita, valor unitário segundo uma unidade de medida, dentre outras variáveis (IEA-SP, 2011).

Para observação dos fenômenos propostos de crescimento e decrescimento entre produção (t) e receita $(R \$)$ foram utilizados métodos de correlação entre as variáveis, também como parte dos dados primários.

Segundo Kogima e Togami (2010) uma função é uma correlação que descreve uma relação causalidade ou mudança. Dentro do contexto da matemática, e mais especificamente relacionado ao agronegócio, o tema funções tem por objetivo estabelecer relações com diversos fenômenos, sejam naturais ou fictícios.

A correlação entre duas variáveis faz-se necessária quando o pesquisador interessa estudar o comportamento conjunto destas variáveis. Distribuindo estes dados em um diagrama construído no plano cartesiano e medindo o grau de correlação entre estas variáveis através do Coeficiente de Correlação de Pearson é possível analisar a correlação entre estas variáveis.

\subsection{Coeficiente de Correlação de Pearson}

O coeficiente de correlação de Pearson, representado por $r$, mede o grau de correlação entre duas variáveis $x \mathrm{e}^{y}$, atribuindo um valor real entre -1 e 1 .

O coeficiente de correlação de Pearson é dada por: 


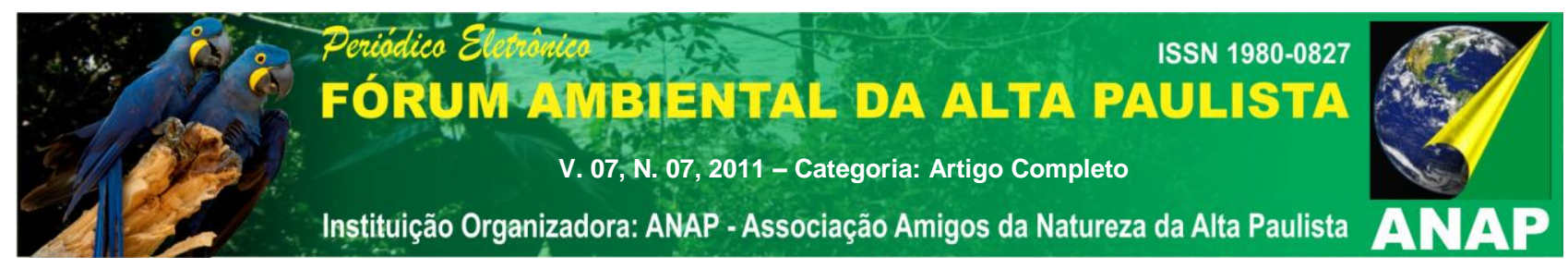

$$
r=\frac{\sum x y-\frac{\sum x \sum y}{n}}{\sqrt{\left(\sum x^{2}-\frac{\left(\sum x\right)^{2}}{n}\right) \cdot\left(\sum y^{2}-\frac{\left(\sum y\right)^{2}}{n}\right)}}
$$

Ao analisar matematicamente a expressão, nota-se que $-1 \leq r \leq 1$. Assim, têm-se três casos a ser considerado:

$$
r=\frac{\sum x y-\frac{\sum x \sum y}{n}}{\sqrt{\left(\sum x^{2}-\frac{\left(\sum x\right)^{2}}{n}\right) \cdot\left(\sum y^{2}-\frac{\left(\sum y\right)^{2}}{n}\right)}}
$$

Se $r=1$ diz-se que duas variáveis $x^{y}$ possuem correlação perfeita positiva.

Se $r=-1$, diz-se que as duas variáveis $x$ e ${ }^{y}$ possuem correlação perfeita negativa.

Se $r=0$, diz-se que não existe correlação entre as variáveis $x$ e ${ }^{y}$.

Para obtenção das informações concernentes ao coeficiente de correlação utilizouse o software Microsoft Excel para a determinação do valor de $r$.

No que tange aos dados secundários, foram utilizadas publicações concernentes à ambos os setores provenientes de algumas instituições tais como Companhia de Tecnologia de Saneamento Ambiental do estado de São Paulo (CETESB) e Agência de Apoio ao Empreendedor e Pequeno Empresário (SEBRAE). Os dados provenientes do Instituto de Economia Agrícola do estado de São Paulo (IEA-SP) e adjunto aos dados secundários foram possíveis identificar em conjunto com os dados primários as causas 


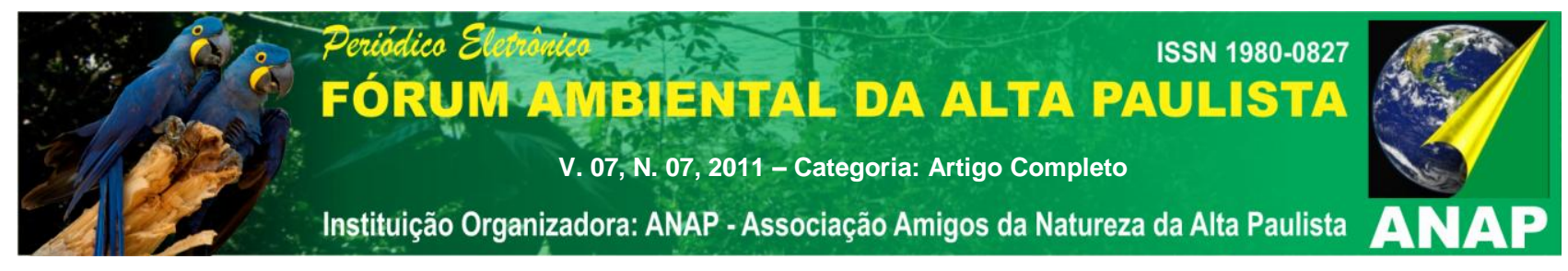

que levaram aos dados numerários referentes a correlação entre a produção de cana-deaçúcar e carne bovina.

\section{RESULTADOS E DISCUSSÕES}

\subsection{Carne bovina}

A seguir são apresentados valores da produção por arroba e preço da carne bovina na região de Tupã - SP entre os anos de 2004 à 2010:

Tabela 1: Evolução da produção da carne bovina na região de Tupã entre 2004 e 2009.

\begin{tabular}{cccc}
\hline Ano & Preço & Produção (Arroba) & Valor da Produção Atualizado (R\$) \\
\hline 2004 & 58,09 & $2.339 .597,00$ & $194.817 .841,11$ \\
\hline 2005 & 53,99 & $2.291 .364,00$ & $177.334 .692,87$ \\
\hline 2006 & 51,65 & $2.149 .632,00$ & $159.155 .165,47$ \\
\hline 2007 & 58,42 & $1.949 .928,00$ & $163.292 .569,26$ \\
\hline 2008 & 81,06 & $1.884 .234,00$ & $218.941 .318,75$ \\
\hline 2009 & 77,71 & $1.962 .048,00$ & $218.561 .081,45$ \\
\hline 2010 & 86,08 & $1.854 .780,00$ & $228.865 .829,98$ \\
\hline
\end{tabular}

Fonte: IEA - SP com valores atualizados.

Esse fenômeno pode ser visto também visto pela representação gráfica das grandezas que são demonstradas nas figuras a seguir: 

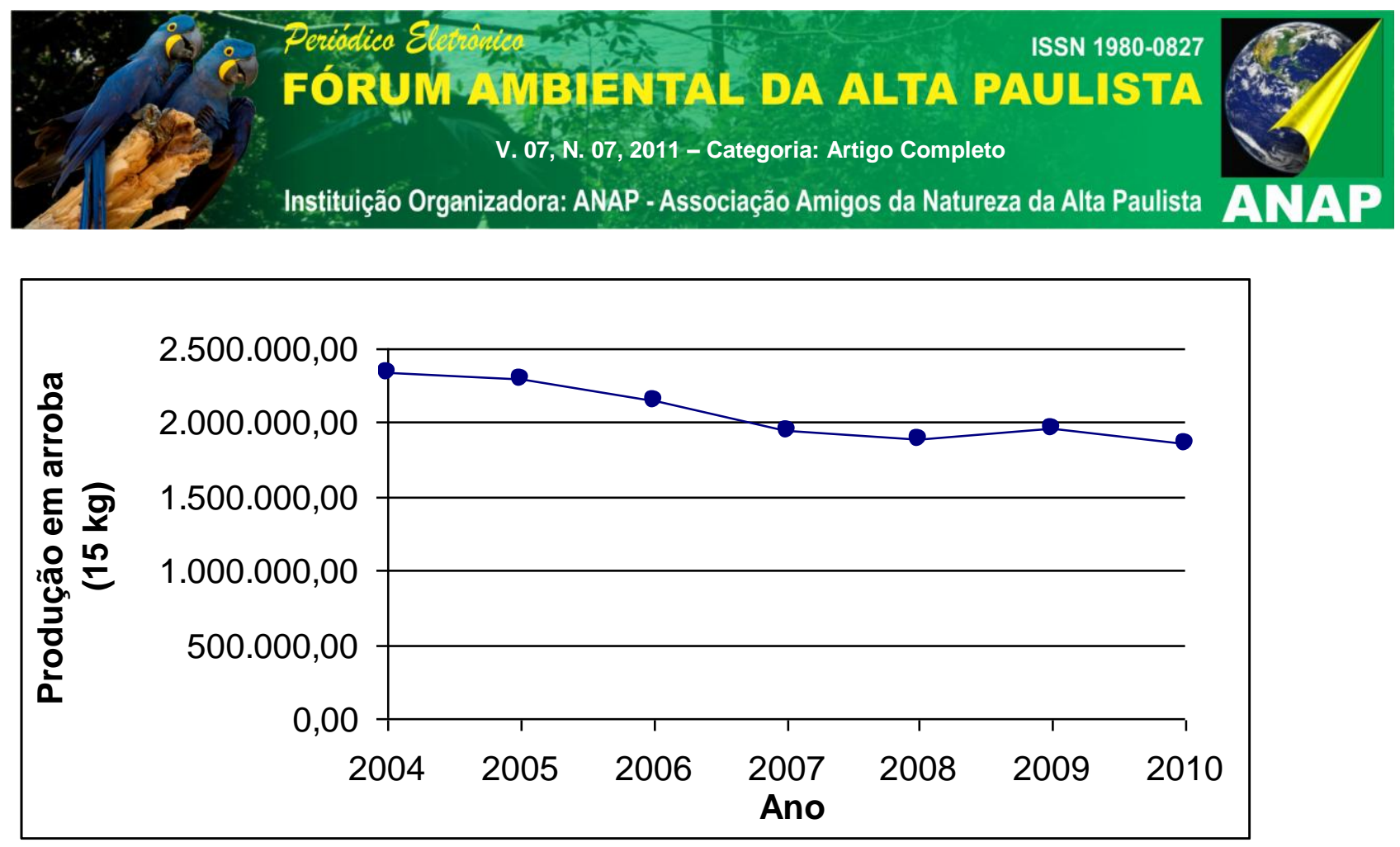

Figura 1: Produção de carne bovina na região de Tupã entre 2004 e 2010.

FONTE: IEA - SP.

No figura 1 nota-se que a produção de carne bovina tem diminuído a sua produção entre os anos de 2004 a 2010 na região de Tupã. Isso já pode ser explicado pela expansão da produção de cana-de-açúcar que será abordado posteriormente.

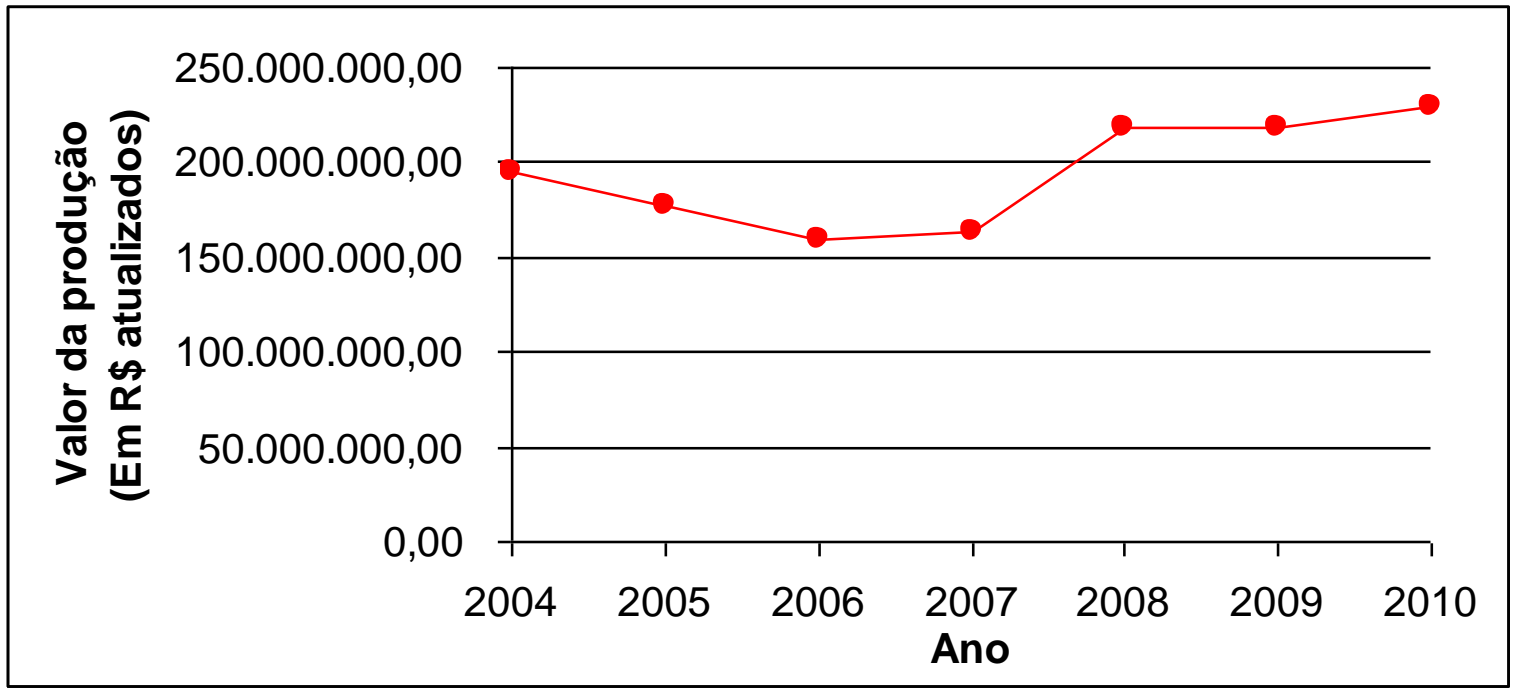

Figura 2: Valor da produção de carne bovina entre 2004 e 2010 (Com valores $R \$$ atualizados). FONTE: IEA - SP. 


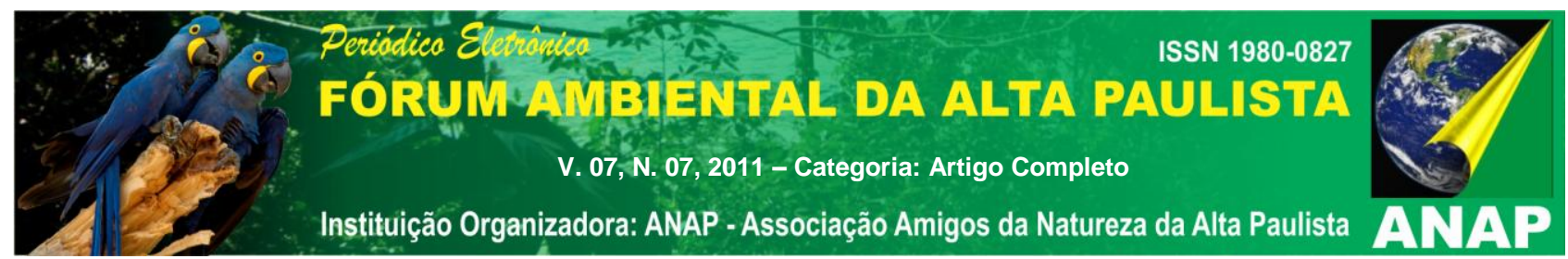

Em contrapartida, nota-se na figura 2 que o valor da produção de carne bovina tem aumentado entre os anos de 2004 à 2010. Além da questão da expansão da cana-deaçúcar esse fato pode ser explicado pela exigência do consumidor final.

Batalha (2007) descreve a cadeia produtiva da carne bovina consistindo em insumos de matéria prima para a alimentação do rebanho, onde o produtor rural é a segunda parte deste elo, e é ele quem vai começar o processo de criação e engorda. Em segundo plano, a carne bovina segue pelo processo de industrialização, onde o mesmo pode ser dividido em duas partes.

A indústria de primeira transformação tem a função de abate e divisão de peças, e a indústria de segunda transformação tem a função de incorporar a carne em produtos produzidos por ela, agregando então valor a elas.

Consoante, a carne bovina pode ser exportada, vendida em varejos como açougues, supermercados e mercearias ou por fim, podem ser encontradas em restaurantes, bares, mercearias, lanchonetes sob a forma de produto com valor agregado, nestes dois últimos casos, todos visando o consumidor final.

Não obstante cabe ressalvar que a estrutura de governança é predominante nesse setor, no que tange principalmente às fiscalizações. Isso faz com que essa cadeia produtiva venha a produzir com mais qualidade para o consumidor final.

Segundo a Pacheco e Yamanaka (2006), dentro deste processo estão em embate a questão do impacto ambiental, no que tange ao consumo de água, energia e produtos químicos utilizados na limpeza de abatedouros, com grande intervenção do governo no que tange a fiscalização.

\subsection{Cana-de-açúcar}

A produção canavieira produz diversos produtos como: etanol, açúcar, cachaça, rapadura, entre outros. 


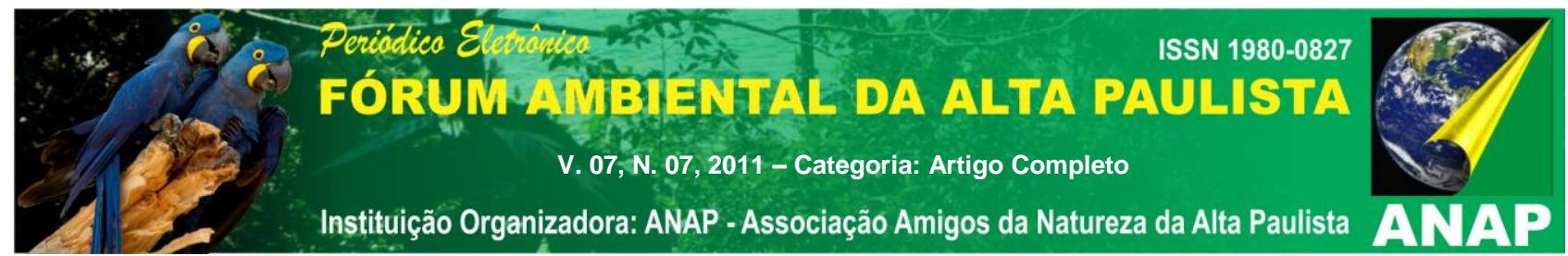

A área produtiva da cana-de-açúcar corresponde a 8,2 milhões de hectares (safra 2010/11), sendo liderados pelo estado de São Paulo com 4,4 milhões de hectare (SANTOS et al, 2010).

A produção de cana-de-açúcar, na safra 2010/2011 foi distribuída em: 54,9 \% (357,5 milhões de toneladas) da lavoura canavieira em etanol, transformando-se em 28,4 bilhões de litros (20,2 bilhões de litros em etanol hidratado e 8,2 bilhões em anidro) e 0 restante convertendo-se em 38,1 milhões de toneladas de açúcar (SANTOS et al, 2010).

Entretanto, na atual safra 2011/2012, a produção canavieira deve cair e a produção destinada ao etanol será de $51 \%$ e o restante para açúcar. Essa queda é justificada principalmente por fatores climáticos como a escassez de chuva em maio, a ocorrência de geadas e o florescimento excessivo (CONAB, 2011).

Em 2009, cerca de 3,3 milhões de metros cúbicos de etanol foi exportada para países da Asía - Pacifico (31,1\%), Europa (28,2\%) e América Central e Sul (23,6\%) (SANTOS et al, 2010).

Devido à diminuição da safra brasileira e indiana de açúcar, há um impacto de valorização em sua cotação internacional. Assim, as usinas estão focando-se na produção de açúcar, afetando conseqüentemente o preço do etanol (CONAB, 2011).

Em relação à cachaça, em 2006, sua produção foi de 1,4 bilhões de litros distribuídos em cerca de 30 mil produtores, que geram 400 mil empregos diretos em um total de 5 mil marcas (SEBRAE, 2008).

A exportação da cachaça corresponde a $1 \%$ de sua produção, sendo os principais países importadores: Alemanha, Estados Unidos, França, entre outros (IBRAC, 2008).

Os estados brasileiros que mais se destacam na produção de cachaça são: São Paulo, Pernambuco, Ceará, Minas Gerais e Paraíba (IBRAC, 2008).

A seguir são apresentados valores da produção por tonelada, bem como o preço da cana-de-açúcar na região de Tupã - SP entre os anos de 2004 à 2010:

Tabela 2: Evolução da produção da cana-de-açúcar na região de Tupã entre 2004 e 2009.

\begin{tabular}{|c|c|c|c|}
\hline Ano & Preço & Produção & Valor da Produção Atualizado \\
\hline
\end{tabular}




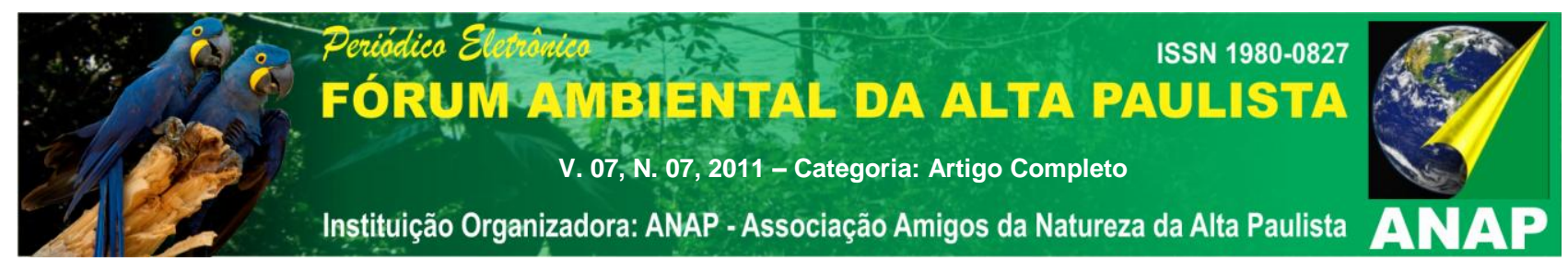

\begin{tabular}{llll}
\hline & (Em R\$) & (Em toneladas) & (Em R\$) \\
\hline 2004 & 35,5 & $1.947 .113,00$ & $105.706 .936,72$ \\
\hline 2005 & 44,95 & $2.460 .640,00$ & $169.145 .951,45$ \\
\hline 2006 & 52 & $2.987 .560,00$ & $237.576 .741,56$ \\
\hline 2007 & 35 & $3.527 .916,00$ & $188.829 .669,87$ \\
\hline 2008 & 36 & $4.343 .098,00$ & $239.103 .596,17$ \\
\hline 2009 & 43 & $5.239 .348,00$ & $344.532 .090,41$ \\
\hline 2010 & 53,2 & $5.679 .448,00$ & $462.063 .579,35$ \\
\hline
\end{tabular}

FONTE: IEA - SP com valores atualizados.

Esse fenômeno pode ser visto também visto pela representação gráfica das grandezas que são demonstradas nas figuras a seguir:

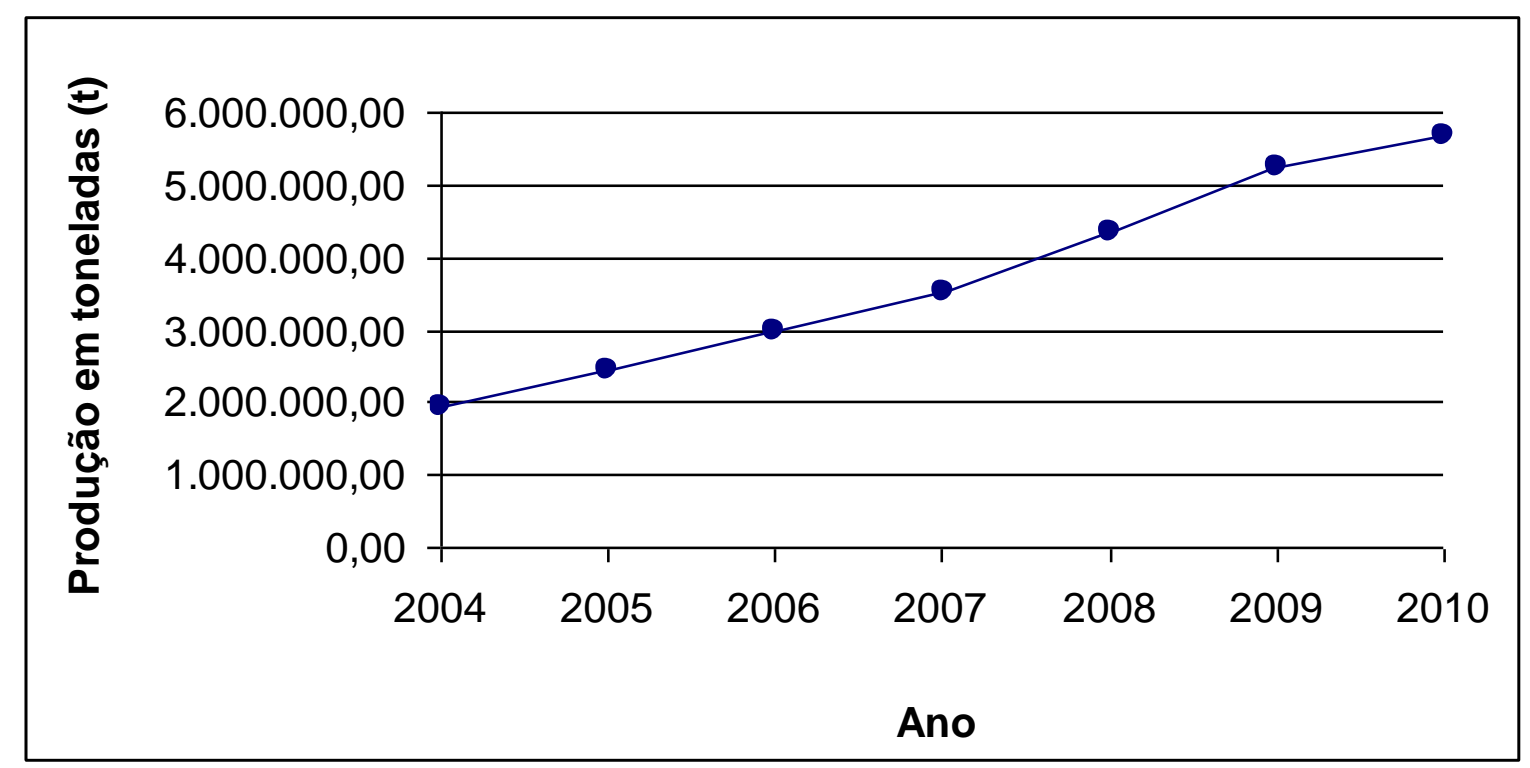

Figura 3: Produção de cana-de-açúcar na região de Tupã-SP entre 2004 à 2010.

FONTE: IEA - SP. 

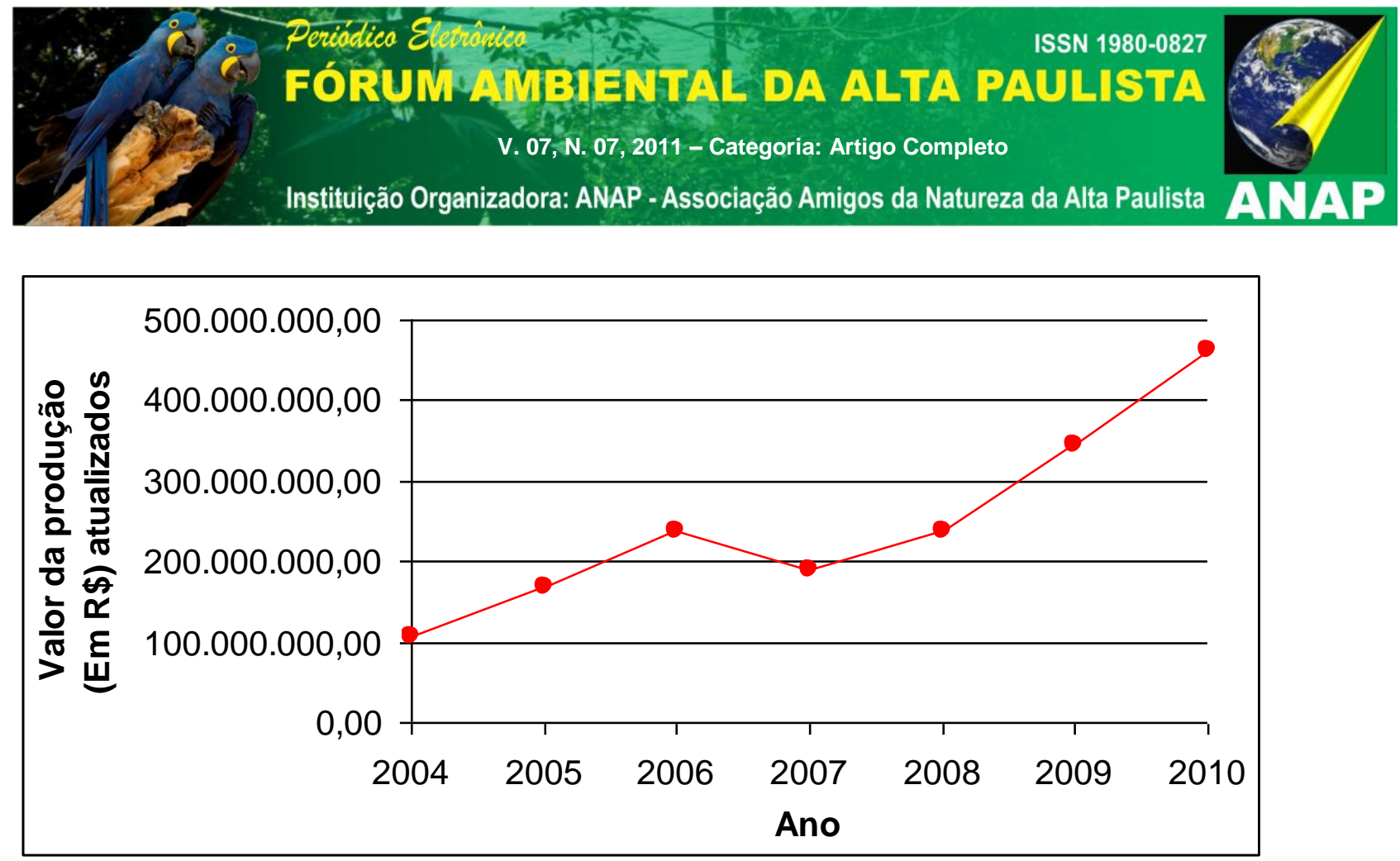

Figura 4: Valor da produção de cana-de-açúcar na região de Tupã - SP entre 2004 à 2010. FONTE: IEA - SP.

Nas ilustrações 3 e 4 respectivamente, nota-se que a produção e o valor da produção de cana-de-açúcar na região de Tupã estão crescendo proporcionalmente. Exceto no período de 2007 à 2008, o valor da cana-de-açúcar sofreu um decréscimo e isso pode ser explicado devido a crise econômica de 2008.

Em suma o crescimento continuo da cana de açúcar pode ser explicado por diversos fatos, assim como o que foi introduzido por Santos et al (2009), que afirma que em aspecto estadual lidera o plantio de cana-de-açúcar com 4,4 milhões de hectares dos 8,2 milhões de hectares utilizados para o plantio do mesmo nacionalmente.

\subsection{Dualidade carne bovina e cana-de-açúcar}

No aspecto matemático a correlação entre a produção de cana-de-açúcar e o valor obtido pela sua venda, é possivel afirmar que tais grandezas não são inversamente proporcionais, diferentemente do que ocorreu com a atividade pecuaria (carne bovina).

A partir dos dados da carne bovina e da cana-de-açúcar, pode-se montar um gráfico demonstrando o comportamento da produção de ambas atividades (gráfico 3). 

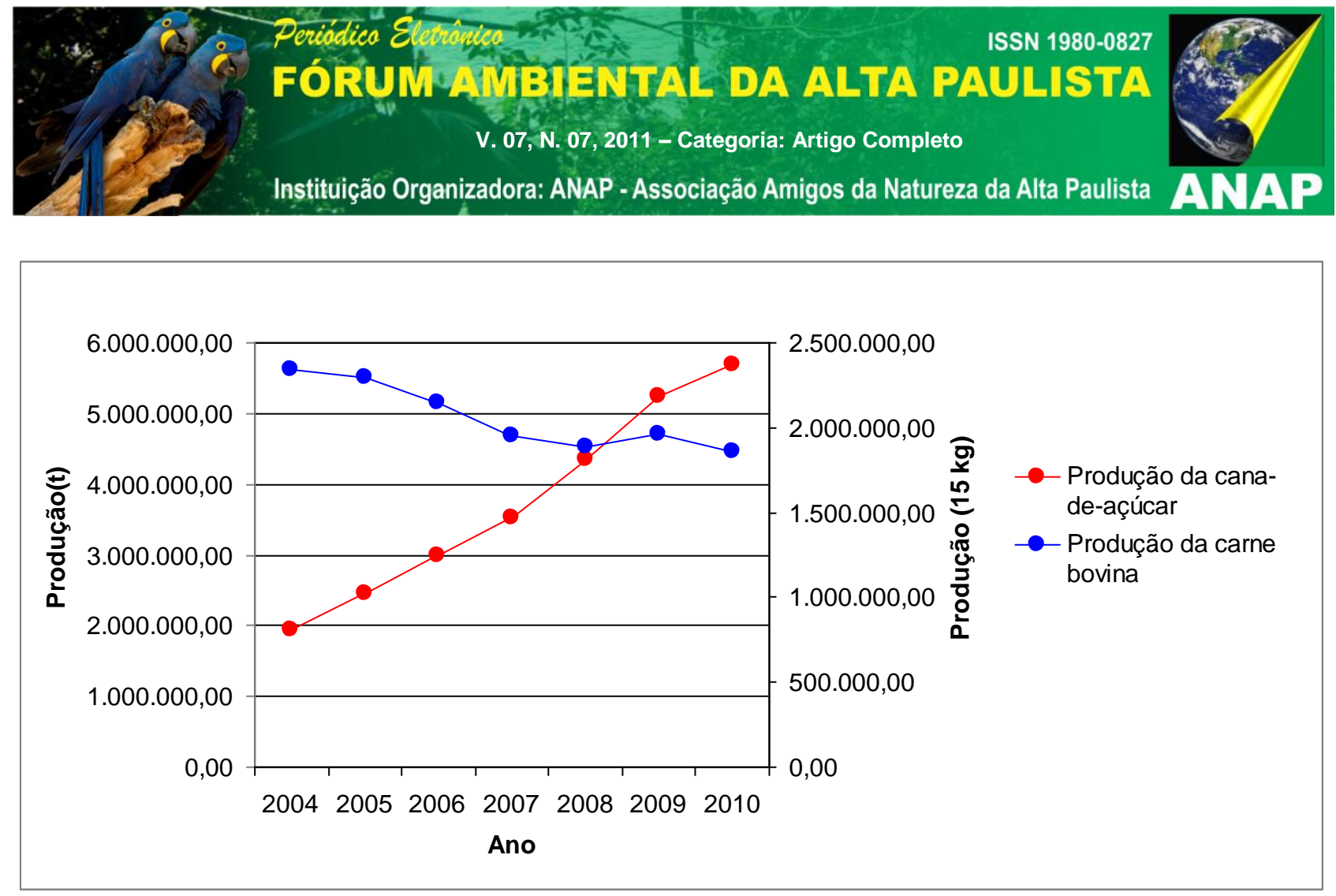

Figura 3:Relação da produção da cana-de-açúcar e da produção da carne bovina na EDR de Tupã entre os anos de 2004 à 2010.

FONTE: IEA - SP.

Com a análise gráfica, pode-se afirmar que a produção de cana-de-açúcar aumentou e a produção de carne bovina diminuiu. Tal comportamento pode ser confirmado pelo coeficiente de Pearson no valor de - 0,8958, caracterizando uma correlação negativa próxima de -1 , ou seja, as variáveis são inversas, sendo que a produção da cana-de-açúcar cresceu positivamente e a produção bovina decresceu.

Os outros motivos do crescimento da produção de cana pode ser explicado por diversos fatores. Segundo Aguiar et al (2009), a cana-de-açúcar apresentou um aumento de produção de 69\% entre os anos de 2004 a 2009 no Brasil. Este aumento pode ser explicado pela expansão da demanda do etanol proveniente do aumento das vendas de veículos bicombustíveis, inseridos no mercado brasileiro em 2003; e das exportações do etanol (RODRIGUES; RODRIGUES, 2008).

Para Torquato (2006), a expansão da cultura da cana-de-açúcar, principalmente no estado de São Paulo, foi fruto da ocupação de áreas de pastagens que ficaram mais eficientes, ocupando menos terras para um determinado rebanho, liberando espaço para a cana-de-açúcar. 


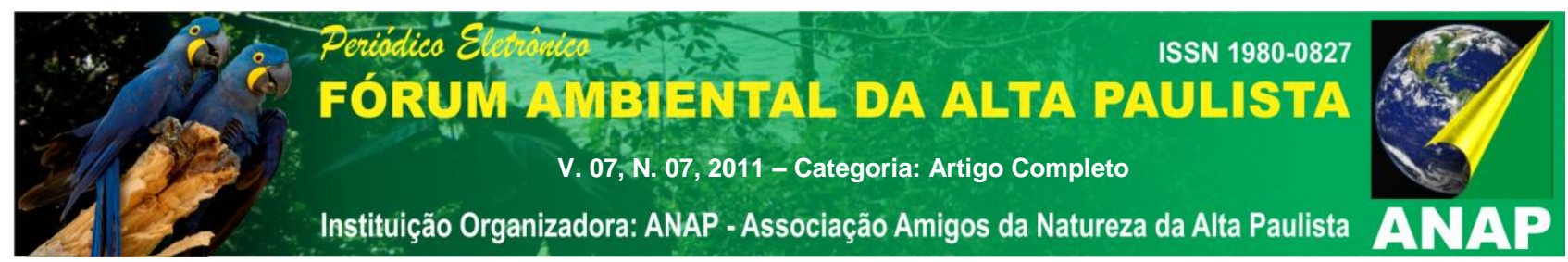

Além da questão dos veículos biocombustíveis, a possibilidade de produção de energia elétrica a partir do bagaço da cana-de-açúcar também impulsionou a expansão da cultura canavieira (TORQUATO, 2006).

Possivelmente, frente ao exposto, pode-se inferir que o aumento da produção de cana-de-açúcar implicou na necessidade de maiores áreas para seu cultivo, acarretando na diminuição das áreas destinadas a práticas da pecuária, implicando assim a diminuição da carne bovina.

\section{CONCLUSÃO}

Desta forma, é possível que o aumento do preço da arroba seja efetivamente causado pelo aumenta de produção de cana-de-açúcar. É importante ressaltar que a diminuição da produção de carne ocasionou um aumento no seu valor por arroba, fenômeno não observado com a cultura da cana-de-açúcar.

Caso esta possibilidade realmente fosse provada por também outros estudos econômicos e pesquisa de campo com proprietários de terra, o custo citado do aumento do preço da carne para a população poderia ser amenizado por eventuais políticas publicas de aumento de impostos para usinas de beneficiamento de cana-de-açúcar e diminuição de impostos para pecuaristas produtores de carne bovina, adicionalmente a programas de diminuição de impostos a insumos voltados à pecuária.

\section{REFERÊNCIAS}

AGUIAR, D. A.; SILVA, W. F.; RUDORFF, B. F. T.; SUGAWARA, L. M.; CARVALHO, M. A. Expansão da cana-de-açúcar no Estado de São Paulo: safras 2003/2004 a 2008/2009. In: SIMPÓSIO BRASILEIRO DE SENSORIAMENTO REMOTO, 14. (SBSR), 2009, Natal. Anais... São José dos Campos: INPE, 2009. p. 916. DVD, On-line. ISBN 978-85-17-00044-7. (INPE-15801-PRE/10411). Disponível em: <http://urlib.net/dpi.inpe.br/sbsr@80/2008/11.17.18.21>. 


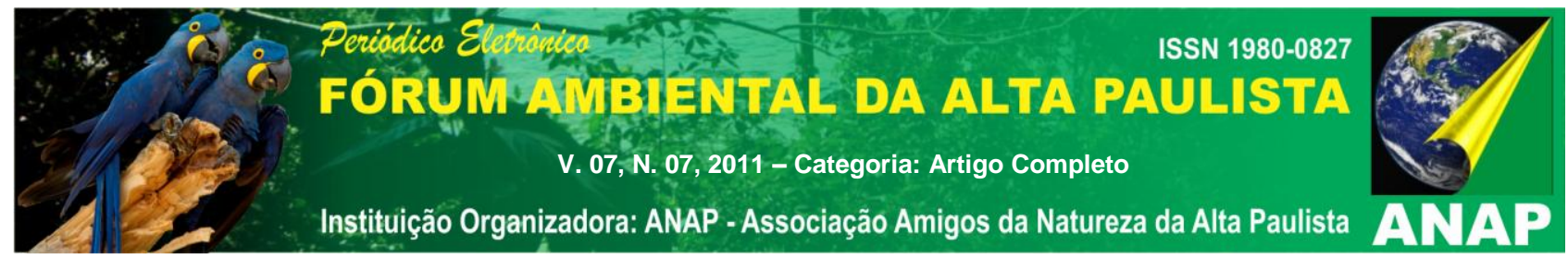

BRASIL. Companhia Nacional de Abastecimento. Perfil do Setor do Açúcar e do Álcool no Brasil: situação observada de novembro de 2007 a abril de 2008, Brasília: CONAB, 2008, 76 p.

BUAINAIN, A. M.; BATALHA, M. O. (Coord.). Cadeia produtiva da carne bovina. Ministério da Agricultura, Pecuária e Abastecimento, Secretaria de Política Agrícola, Instituto Interamericano de Cooperação para a Agricultura. Brasília : IICA ; MAPA/SPA, 2007. Disponível em: < http://www.iica.org.br/Docs/CadeiasProdutivas/Cadeia\%20Produtiva\%20da\%20Carne\%20Bovina\%20c\%20c apa.pdf>. Data de acesso: 15 ago. 2011.

Companhia Nacional do Abastecimento (CONAB). Acompanhamento da safra brasileira: cana-de-açúcar, segundo levantamento, agosto/2011. Brasília: CONAB 2011.

IBGE. Banco de dados agregado. Disponível em:

$<h t t p: / / w w w . s i d r a . i b g e . g o v . b r / b d a / p e c u a / d e f a u l t . a s p ? t=2 \& z=t \& o=24 \& u 1=1 \& u 2=1 \& u 3=1 \& u 4=1 \& u 5=1 \& u 6=1 \&$ $u 7=1>$. Data de acesso: 10 set. 2011.

IBRAC. Mercado de Cachaça. 2009. Disponível em:

$<$ http://www.ibrac.net/index.php?option=com_content\&view=article\&id=130:mercado-de-

cachaca\&catid=3:noticias\&ltemid=57> Data de acesso: 10 ago. 2011.

INSTITUTO DE ECONOMIA AGRíCOLA - IEA. Banco de dados. São Paulo: IEA, 2011. Disponível em: $<$ http://ciagri.iea.sp.gov.br/bancoiea/subjetiva.aspx?cod_sis=1\&idioma=1>. Data de acesso: 7 jun. 2011.

MARCONI, M. A.; LAKATOS, E. M. Fundamentos de metodologia científica. $5^{a}$ ed. São Paulo: Atlas, p.195-199, 2003.

PACHECO, JOSÉ WAGNER; YAMANAKA, HÉLIO TADASHI. Guia técnico ambiental de abates (bovino e suíno). São Paulo: CETESB, 2006. 96p . Disponível em: <

http://www.cetesb.sp.gov.br/tecnologia/producao_limpa/documentos/abate.pdf >.

PACHECO, JOSÉ WAGNER; YAMANAKA, HÉLIO TADASHI. Guia técnico ambiental de frigoríficos industrialização de carnes (bovina e suína). São Paulo: CETESB, 2006. 85p. 20-21. Disponível em: < http://www.cetesb.sp.gov.br/tecnologia/producao_limpa/documentos/frigorifico.pdf >.

RODRIGUES, A. P.; RODRIGUES, L. A nova agenda do setor sucroenergético: o etanol e os desafios do mercado interno. AgroAnalysis. V. 28, n.08, p.19-36, 2008. 


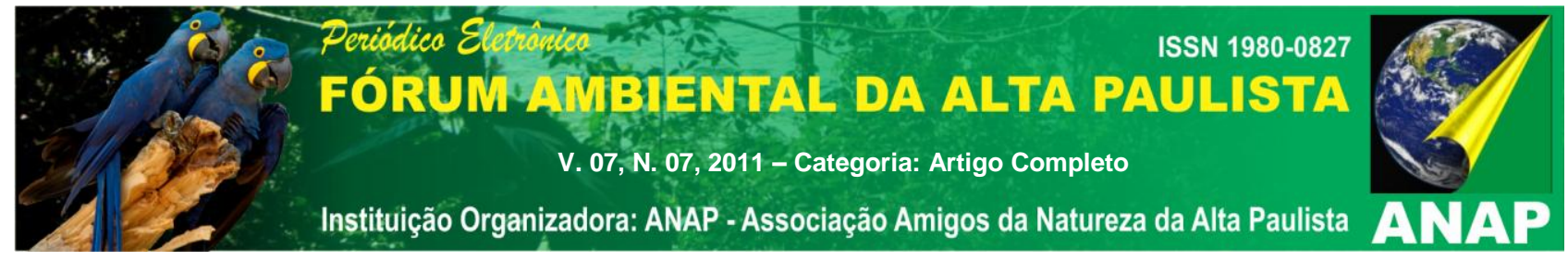

SANTOS, CLEITON; et al. Anuário Brasileiro Da Cana-De-Açúcar 2010. Santa Cruz do Sul: Editora Gazeta Santa Cruz, 2010. 136p. Disponível em:

<http://www.anuarios.com.br/upload/publicacaoCapitulo/pdfpt/pdf543.pdf >

SEBRAE. Cachaça Artesanal. 2008. Disponível em:

<http://201.2.114.147/bds/BDS.nsf/32D45A5E7EE50293832574DC004574B0/\$File/NT0003905A.pdf>. Data de acesso: 18 ago. 2011.

TORQUATO, S. A. Cana-de-açúcar para indústria: o quanto vai precisar crescer. Instituto de Economia Agrícola do estado de São Paulo (IEA-SP). Disponível em: <

http://www.iea.sp.gov.br/out/verTexto.php?codTexto=7448>. Acesso em: 5 ago. 2011. 